\title{
CDNA Library
}

National Cancer Institute

\section{Source}

National Cancer Institute. CDNA Library. NCI Thesaurus. Code C15727.

A collection of DNA molecules that have been cloned in vectors. In the case of a cDNA library the DNA inserts are copies of RNAs that have been reverse-transcribed into DNA prior to cloning. 